\title{
AMETRINE: a humanitarian camp management system
}

\author{
F. Aligne, J. Dréo \& J. Mattioli \\ Decision Technologies \& Mathematics Laboratory, \\ Thales Research and Technology, France
}

\begin{abstract}
In human made or natural disasters, two of the main stumbling blocks that impede humanitarian action are the poor situation assessment and organisational problems. The difficulty of performing an overall situation assessment often results in misinterpretation and inadequate engagement and action. This lack of efficiency has been outlined by the poor coordination of international aid in the Sri Lanka tsunami in 2004.

Citrine project (2006 PASR European project selected in the security theme) addressed these issues and aimed to support the crisis management process in mitigation, damage assessment and preliminary recovery phase, focussing on humanitarian activities provided by NGOs and Health Services.

This paper presents the outcomes of the research carried in Citrine to define Ametrine, a decision support module for the management of humanitarian operations in a disaster land.

First, the research was dedicated to collect the end-user needs and to find out how the situation can be assessed, monitored and controlled for a humanitarian camp. This was performed so as to follow as close as possible the UNHCR general recommendations (issued from the UNHCR handbooks), the overall goal being to ensure that the fundamental rights of the displaced people and refugees are fulfilled.

Based on this analysis, Ametrine addresses the tactical level and is devoted to the set-up and the management of a camp of refugees. Ametrine analyses and provides information and decision support on most aspects of camp operations management, to ensure the access to water, environmental sanitation, shelter, food and health services. Ametrine thus achieves four tasks beyond data
\end{abstract}


presentation: resources and needs assessment, resources and needs prediction, resources allocation and alarms triggering.

Ametrine has been built as an independent module that can be integrated either as one additional module of the Sahana open source software (www.sahana.lk), or on the Citrine platform.

Keywords: humanitarian camp management, refugee camp, decision support, resources allocation, situation assessment, tactical management, operations research.

\section{Introduction}

Nowadays, humanitarian action is impaired by delay due to poor situation assessment and by organisational problems due to lack of coordination between all involved agencies (NGO, Health Services, Civil Protection, Local Authorities...). New threats introduced by terrorist groups increase the complexity to anticipate appropriate response plans due to unpredictable modus operandi. When assessing the situation each agency addresses partially the situation with regards to its domain of expertise. No overall situation assessment is performed, which often results in misinterpretation and inadequate engagement and action. This lack of efficiency has been outlined by the poor coordination of international aid in the Sri Lanka tsunami in 2004.

One of the 2006 PASR selected project, Citrine, addresses these issues and aims to support the crisis management process in mitigation, damage assessment and preliminary recovery phase, focusing on humanitarian activities provided by NGOs and Health Services.

This paper presents the Citrine decision support module: Ametrine, a decision support system for the management of humanitarian operations in a disaster land, that has been defined and developed in the context of the project. The Ametrine system provides some facilities at a tactical level to enhance the set-up and management of a humanitarian camp of internally displaced people.

The paper is structured as follow: the first section introduces the Ametrine system in the context of the Citrine PASR project, the second section details the objectives, scope and facilities of the Ametrine system, the third part presents the resulting Ametrine system functionalities.

\section{Ametrine, a tactical decision support tool for humanitarian operation management}

Ametrine has been elaborated in the context of the Citrine project, which is one of the 15 security research projects selected by the European Community in the Preparatory Action for Security Research (PASR) 2006. Citrine project, Common Intelligence and Traceability for Rescues and IdentificatioN opErations, started in January 2007 and finished in June 2008.

The Citrine project aimed at developing a first version of an integrated set of share information management tools and models to facilitate the efficient 
integration of diverse emergency and management services for humanitarian activities operations and rescue tasks in support of the external policies of the EU, with an emphasis on security aspects and attention to organizational structures, inter-organizational co-ordination and communication, distributed architectures and human factors.

Citrine encompasses at the co-ordination level:

- tools for gathering and merging any type of available information coming from European and National agencies, organizations and citizens,

- decision aid tools to support logistic operations and work planning,

- information sharing tools;

and, at the tactical level:

- relevant tools to produce a comprehensive humanitarian oriented, real time situation assessment,

- decision aid tools to dispatch casualties and evacuated populations and optimise the use of rescue.

To achieve Citrine overall objectives, a decision support module has been developed, that aims to enable users to better select appropriate strategies and tactics, to better determine course of actions, to predict possible reactions and consequences, to optimise the allocation of limited resources, to provide explanation of decisions made, to reduce uncertainty and speed up reasoning processes, at both co-ordination and tactical level.

AMETRINE (Assistance Management Enhanced Tool for Refugees and INternally displaced pEople camps) addresses the tactical level, and is devoted to the set-up and management of a humanitarian camp of Internally Displaced Persons (IDP) or refugees.

Ametrine system analyses and provides information and decision support on all aspects of camp operations management, to facilitate the camp manager and camp team tasks. It provides assistance to the camp management to ensure the access to water, environmental sanitation, shelter, food and health services. So far, the Ametrine system does not provide any facility for the prevention and treatment of disabilities, the protection and threat to security, education opportunities, camp closure and documentation, facilitating formation of camp committees.

A detailed description of Ametrine scope and facilities is presented hereafter.

\section{Ametrine objectives, scope and facilities}

The Ametrine decision support system addresses the tactical level, and is devoted to the set-up and management of a humanitarian camp of internally displaced persons or refugees. This section presents, first the general objectives and scope, then the general assumptions made on Ametrine scope, the underlying methodology of the Ametrine system, and camp management global issues that are addressed by the system. 


\subsection{Scope and objectives}

The objective of Ametrine is to analyse and provide information and decision support on all aspects of camp operations management to facilitate the camp manager and camp team tasks. Ametrine aims to facilitate situation assessment, need assessment and resources allocation by providing information analysis and displays, checklists, guidelines, resources management programs, monitoring aids and alarm triggers.

Ametrine system covering goes from daily operations to global camp management forecast both in emergency and reconstruction phases. It addresses all actors involved in the running of the camp.

The camp management must ensure that the fundamental rights of the displaced people are fulfilled. It involves a wide range of responsibilities; in particular it has to ensure the provision of services and facilities to meet basic needs such as water, health, environmental sanitation, shelter, food, education, protection and security.

The Ametrine system provides assistance to the camp management to fulfil the following points:

- Access to Water: ensure the access to a sage and sustainable supply of water for drinking/cooking, as well as for bathing and washing.

- Environmental sanitation: ensure the availability of sanitary facilities such as taps and wash basins, soap, latrines.

- Shelter: ensure the availability of adequate temporary shelters in line with standards concerning space and privacy.

- Food: ensure that the camp residents receive the adequate amount and quality of food, as well as cooking fuel and utensils.

- Health services: ensure that the camp residents have access to the adequate medicine.

- Accountability: ensure the maintenance of accurate and up-to-date information relevant to the camp management.

\subsection{General assumptions}

The camp location selection is outside the scope of the Ametrine system and shall be considered as a pre-requisite. "Often however, the camp management agency comes in when the camp planning process is largely completed and will implement what has already been planned" (Camp Management Toolkit [1]).

The system has been designed to be as close as possible to the general recommendations of the UNHRC. When used on the field, it is the responsibility of the users to ensure that the outcomes of the system will respect all the agreement that have been entered during the camp negotiations and planning process. In particular, the users will check that the Memorandum of Understanding is not infringed by any of the system outputs.

The Ametrine system is designed to provide decision supports for ensuring the provision of services and facilities to meet basic needs such as water, health, 
environmental sanitation, shelter and food. Education, protection and security have not been addressed so far.

\subsection{Underlying system methodology}

A careful analysis of refugees camp management has been conducted based on the end-user requirements collection, and on references [1-6] readings. The resulting features of the system have been validated by the Portuguese NGO, AMI, which was participating in the Citrine project.

The Ametrine system process is a well known procedure in the decision aids sciences, it consist, for each of the points addressed (camp set-up, food, medicine, etc.), of four main steps:

1. camp management resources assessment,

2. camp management needs assessment,

3. optimisation of the fulfilment of the needs by the resources,

4. camp management support and planning assessment, and alarm triggering.

\subsection{Camp management global issues}

\subsubsection{Camp set-up}

The fundamental goal to design the camp set-up is to provide a safe, secure and dignified place for IDPs and refugees.

As set in the general assumptions, the Ametrine system does not address the camp management location selection. The camp location selection should have been done in accordance with the required size of the site, access roads, location, topography, soil type, vegetation and environmental aspects.

However the Ametrine system provides an evaluation of the global camp needs in term of water, shelters and sanity issues. This might contributes to the overall analysis and forecast of a region situation assessment and provide material for the modification, moving or closure of the camp.

\subsubsection{Camp residents registration}

The registration of the refugees and internally displaced persons is a key input information for the whole Ametrine system. Registration of people first contributes to protect the camp residents, to ensure them access to basic rights and family reunification, to identify persons in need of special assistance, to identify and assist unaccompanied children. It is a fundamental tool to determine the size and characteristics of camp residents group, and has thus a key role in the setting and management of a camp.

As such, the size of a camp impacts the camp planning programs and operational inputs and monitoring and evaluation of results. Inputs include food and non-food items, while operational inputs include funding level, number of staff, etc. Monitoring and evaluation results depend on the population number estimation to measure for example the mortality, health level, latrine coverage, etc. 
The characteristic of a population (gender, age, group belonging) contributes to optimise the camp programs and management by adapting the assistance to the different communities (vulnerable persons, people with physical and mental disabilities, the elderly, unaccompanied children, single female parents, single females...).

The Ametrine system thus follows the UNHCR registration methodology [3] to adjust and optimise the parameters used in the needs estimations procedures.

\subsubsection{Food distribution}

Ensuring access of camp residents to food and proper nutrition is one of the first priorities in any camp setting, particularly in emergency settings. A clear knowledge of the food needs assessment is one of the key issues of the camp management.

Ametrine system addresses the food need assessment procedure, and support to plan and monitor the food availability. The food needs assessment carried out is based on the residents' registration database.

\subsubsection{Health care and sanitation}

Adequate water and sanitation (WATSAN) facilities are among the vital services that need to be addressed from the earliest stages of a camp. These issues should not only be addressed for the camp set-up, but also monitored and forecasted at each phase to anticipate vital health troubles and plan solutions. The camp management must also ensure that appropriate health care is available for all camp residents.

Following the recommendations of the World Health Organization (WHO), 'Guidelines for Drug Donations' [8], all drugs provisions shall be based on an expressed need and be relevant to the disease pattern in the recipient country. In acute emergencies the need for prior need estimation by the recipient may be waived, provided the drugs are amongst the "WHO Model List of Essential Drugs' [9].

In the acute phase of an emergency, or in the phase of displacements of refugee population without any medical care, it is recommended to use the standardized kit of drugs and medical supplies: 'Emergency Health Kit 2006' [7]. This kit contains drugs, disposal supplies and basic equipment need for general medical care for a population from 1000 or 10000 persons, for three months. In the running phase a more adapted health management analysis might be derived, based on the 'WHO Model List of Essential Medicines'.

To achieve these objectives, the Ametrine system participates to:

- ensure that sufficient drinking water is available, and the storage capacity is consistent with the population size ;

- ensure the number of toilets and garbage matches the standard requirements ;

- $\quad$ ensure that the medical and hygienic intendancy is available (medicines, soap, condoms, etc.). 


\section{Ametrine functionalities}

\subsection{Definitions}

The key notions of the Ametrine decision support module system are the store and the item. A store refers to a repository of resources and may belong to a NGO. A resident is associated to a store if the resources used to satisfy its needs are taken from this store.

An item is any resource involved to fulfil the camp management goal, that is to ensure the provision of services and facilities to meet the refugees' basic needs (water, shelters, blanket, rice...). Items may be clustered in item types (set-up, water, food, medical). Items are associated with a store.

\subsection{Global architecture}

The Ametrine decision support system has been built as an independent module that can be integrated either as one additional module of the Sahana software [10], either on the Citrine integrated platform. Defined as a Web application, is only requires to get an occasional internet connection to be operational on field (we expect that once a day could be sufficient).

The Ametrine decision support system targets several NGOs, each of them managing several stores, which contain different types of items. The Ametrine system achieves four tasks beyond data presentation:

- Resources and needs assessment: considering the parameters of the system (number of individuals associated with a store, amount of resources in the stores, etc.), a model is used to specify the resources and needs of each item, at items or stores level.

- Resources and needs prediction: considering the needs and their past evolution, a temporal prediction of the population is performed to estimate the future resources needs.

- Resources allocation: considering the state of the systems and the predicted needs, an optimal allocation of available resources is computed.

- Alarms triggering: considering the item and indicators estimation and prediction, some alarms are activated if the UNHCR recommendations are infringed.

The decision support and planning is provided and assessed on the base of the UNHCR indicators (see [4].

The system outputs are tables, graphics, Gantt chart and maps, presented in HTML web pages.

\subsection{Ametrine modules}

Once a set of stores selected, the user chooses access to Ametrine functionalities: resources and needs assessment, needs forecast, resources allocation and alarm triggering. 


\subsubsection{Estimation module}

The resources assessments are based on one side on the availability of items in stores (provided by Citrine's database) and on the other side, on some data completion process.

The needs assessments are established by taking into account the refugees estimated consumption using linear functions adjusted on the indicators of the UNHCR and WHO standards recommendation. For each item, a specific function is used, that takes into account the number of individuals associated to the store and the characteristics of the item consumption.

Resources and needs assessment are provided in table sheets, for different combinations of item and stores as presented in Figure 1.

\subsubsection{Prediction module}

Resources and needs prediction are assessed by the Ametrine prediction module by a set of time functions. Considering the resources, needs estimation and a model of the population evolution based on Gaussian functions, a temporal prediction is provided.

Resources and needs prediction analysis are provided in table sheets, for different combinations of item and stores.

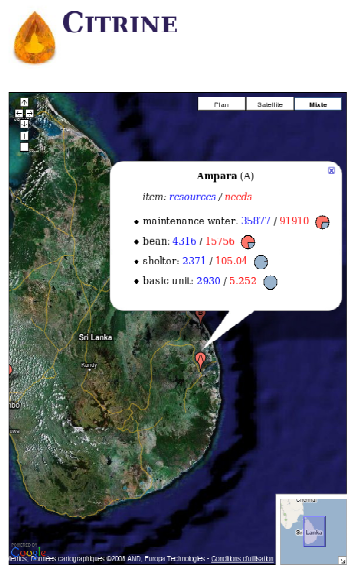

Figure 1: $\quad$ Estimation module of AMETRINE.

\subsubsection{Resources allocation module}

On the base of the estimation and prediction of the resources and needs, an allocation of available resources is performed to propose an optimised resources distribution either at a store level, or at a base level.

Decision support techniques are applied to optimise the allocation of resources, which is modelled as a temporal planning problem. In the model, trucks are dispatching resources among camps, taking into account their needs. The mathematical model is expressed in the PDDL standard language [11]. Two solvers are used, namely an exact constraint programming and a genetic algorithm using decomposition techniques and hybridicized with the preceding 
algorithm [12]. The system is capable of approximating a feasible solution to a problems with 5 camps and 5 trucks in approximately half an hour. The exact optimum may be found within several hours or a week, depending of the instance.

Suggestion of optimised resources allocation is provided in a Gantt chart.
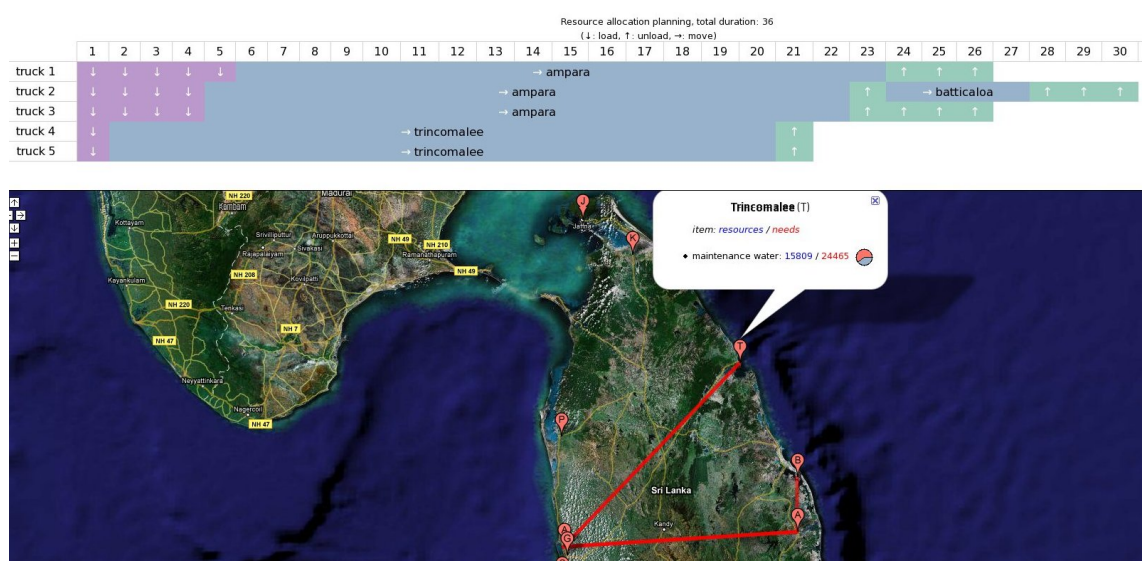

Figure 2: $\quad$ Allocation module in AMETRINE.

\subsubsection{Alarms triggering module}

Item and indicators estimation and prediction are monitored and compared to some references levels. These references levels are taken out for e.g. the UNHRC recommendations. In case the items and indicators do not satisfy the standard recommendations, some alarms are activated.

Alarms lists records are listed and provided in table sheets.

\section{Conclusion}

This paper has presented a decision module support system, Ametrine, that was developed in the Context of Citrine PASR project. This system contributes to improve and facilitate the monitoring, forecast and management of refugees' camps, and enable an efficient organisation and coordination of humanitarian operations and rescues tasks in a crisis context.

Ametrine thus achieves four tasks beyond data presentation: resources and needs assessment, resources and needs prediction, resources allocation and alarms triggering.

This support system participates to the definition of a global information system that will provide an overall situation assessment and enhance rescue coordination. 


\section{References}

[1] “Camp Management Toolkit”, NRC (Norwegian Refugee Council), 2004.

[2] "UNHCR Handbook for emergencies", UNHCR (United Nations High Commissioner for Refugees, Genève, 2e edition, June 2000.

[3] "UNHCR Handbook for registration", UNHCR (United Nations High Commissioner for Refugees, Genève, provisional release, September 2003.

[4] "Project Planning in UNHCR. A Practical Guide on the Use of Objectives, Outputs and Indicators, UNHCR", Genève, 2e version, March 2002.

[5] "Practical Guide to the Systematic Use of STANDARDS \& INDICATORS in UNHCR Operations", UNHCR (United Nations High Commissioner for Refugees, 2e edition, February 2006.

[6] "Memorandum of Understanding" between the Office of the United Nations Commissioner of Refugees (UNHCR) and the World Food Programme (WFP), Genève-Rome, July 2002.

[7] "The Interagency Emergency Health Kit 2006", Third edition 2006, WHO/ PSM/PAR/2006.4, http://www.who.int/medicinedocs/collect/edmweb/pdf /s13486e/s13486e.pdf.

[8] “Guidelines for Drug Donations", Revised 1999, WHO/EDM/PAR/99.4.

[9] "WHO Model list of Essential Medicines", 15th list, March 2007, http://www.who.int/medicines/publications/EML15.pdf.

[10] Sahana 5.2, Free and Open Source Disaster System, www.sahana.lk.

[11] M. Schoenauer, P. Savéant, and V. Vidal, "Divide-and-evolve: A new memetic scheme for domain-independent temporal planning", pages 247 260. 2006

[12] Alfonso E Gerevini, Patrik Haslum, Derek Long, Alessandro Saetti, Yannis Dimopoulos, PDF Deterministic planning in the fifth international planning competition, "PDDL3 and experimental evaluation of the planners", Artificial Intelligence, Vol. 173, No. 5-6. (April 2009), pp. 619-668. 